\title{
A polymorphism of EGFR extracellular domain is associated with progression free-survival in metastatic colorectal cancer patients receiving cetuximab-based treatment
} Anthony Gonçalves ${ }^{* 1,2,6,7}$, Séverine Esteyries ${ }^{\dagger 3,6,7}$, Brynn Taylor-Smedra ${ }^{2,6,7}$, Arnaud Lagarde 3,7 , Mounay Ayadi ${ }^{1}$, Geneviève Monges $4,6,7$, François Bertucci ${ }^{1,3,6,7}$, Benjamin Esterni ${ }^{1,7}$, Jean-Robert Delpero $5,6,7$, Olivier Turrini ${ }^{5}$, Bernard Lelong 5 , Patrice Viens ${ }^{1,6,7}$, Jean-Paul Borg 2,6,7, Daniel Birnbaum ${ }^{3,6,7}$, Sylviane Olschwang ${ }^{3,7}$ and Frédéric Viret ${ }^{1,7}$

Address: ${ }^{1}$ Department of Medical Oncology, Institut Paoli-Calmettes, Marseille, France, ${ }^{2}$ Department of Molecular Pharmacology, Institut PaoliCalmettes, Marseille, France, ${ }^{3}$ Department of Molecular Oncology, Institut Paoli-Calmettes, Marseille, France, ${ }^{4}$ Department of BioPathology, Institut Paoli-Calmettes, Marseille, France, ${ }^{5}$ Department of Surgical Oncology, Institut Paoli-Calmettes, Marseille, France, ${ }^{6}$ Université de la Méditerranée, UFR de Médecine, Marseille, France and 7INSERM U891; Centre de Recherche en Cancérologie de Marseille, Marseille, France

Email: Anthony Gonçalves* - goncalves.anthony2@orange.fr; Séverine Esteyries - esteyries@marseille.inserm.fr; Brynn TaylorSmedra - brynntaylor@hotmail.com; Arnaud Lagarde - lagarde@marseille.inserm.fr; Mounay Ayadi - oncomed@marseille.fnclcc.fr; Geneviève Monges - mongesg@marseille.fnclcc.fr; François Bertucci - bertuccif@marseille.fnclcc.fr; Benjamin Esterni - esternib@marseille.fnclcc.fr; Jean-Robert Delpero - delperojr@marseille.fnclcc.fr; Olivier Turrini - turrinio@ marseille.fnclcc.fr; Bernard Lelong - lelongb@ marseille.fnclcc.fr; Patrice Viens - viensp@marseille.fnclcc.fr; JeanPaul Borg - borg@marseille.inserm.fr; Daniel Birnbaum - birnbaum@marseille.inserm.fr; Sylviane Olschwang - olschwangs@marseille.fnclcc.fr; Frédéric Viret - viretf@marseille.fnclcc.fr

* Corresponding author †Equal contributors

Published: 10 June 2008

BMC Cancer 2008, 8:169 doi:10.1186/147/-2407-8-169
Received: 21 October 2007

Accepted: 10 June 2008

This article is available from: http://www.biomedcentral.com//47/-2407/8//69

(C) 2008 Gonçalves et al; licensee BioMed Central Ltd.

This is an Open Access article distributed under the terms of the Creative Commons Attribution License (http://creativecommons.org/licenses/by/2.0), which permits unrestricted use, distribution, and reproduction in any medium, provided the original work is properly cited.

\begin{abstract}
Background: Cetuximab, a monoclonal antibody targeting Epidermal Growth Factor Receptor (EGFR), is currently used in metastatic colorectal cancer (mCRC), but predictive factors for therapeutic response are lacking. Mutational status of KRAS and EGFR, and EGFR copy number are potential determinants of cetuximab activity.

Methods: We analyzed tumor tissues from 32 EGFR-positive $m C R C$ patients receiving cetuximab/ irinotecan combination and evaluable for treatment response. EGFR copy number was quantified by fluorescence in situ hybridization (FISH). KRAS exon I and EGFR exons coding for extracellular regions were sequenced.

Results: Nine patients experienced an objective response (partial response) and 23 were considered as nonresponders ( 12 with stable disease and II with progressive disease). There was no EGFR amplification found, but high polysomy was noted in 2 patients, both of which were cetuximab responders. No EGFR mutations were found but a variant of exon 13 (R52IK) was observed in 12 patients, II of which achieved objective response or stable disease. Progressionfree and overall survivals were significantly better in patients with this EGFR exon I3 variant. KRAS mutations were found in 14 cases. While there was a trend for an increased KRAS mutation frequency in nonresponder patients (12 mutations out of $23,52 \%)$ as compared to responder
\end{abstract}


patients ( 2 out of $9,22 \%$ ), authentic tumor response or long-term disease stabilization was found in KRAS mutated patients.

Conclusion: This preliminary study suggests that: an increase in EGFR copy number may be associated with cetuximab response but is a rare event in CRC, KRAS mutations are associated with low response rate but do not preclude any cetuximab-based combination efficacy and EGFR exon I 3 variant (R52IK) may predict for cetuximab benefit.

\section{Background}

Epidermal growth factor receptor (EGFR), which participates in signaling pathways that are deregulated in cancer cells, is a promising target in epithelial cancer, notably colorectal cancer [1]. Cetuximab (Erbitux $\left.{ }^{\circledR}\right)$, a monoclonal antibody targeting EGFR, is currently used in EGFRexpressing metastatic colorectal cancer (mCRC) in combination with cytotoxic chemotherapy (irinotecan), after failure of a previous irinotecan-based regimen. In this setting, cetuximab produces objective response in about $25 \%$ of patients, with nearly $30 \%$ of patients achieving disease stabilization [2], resulting in a median progression-free survival of 4 months and a median overall survival of 6 to 9 months. Recently, another EGFR-targeted monoclonal antibody, panitumumab (vectibix ${ }^{\circledast}$ ) was FDA-approved in mCRC as single agent, after failing chemotherapy drugs fluoropyrimidine, oxaliplatin and irinotecan[3]. Panitumumab induces a response rate of $10 \%$, similar to that achieved with single-agent cetuximab in a similar patient population [4,5], and demonstrates a modest but significant increase in median progressionfree survival against best supportive care.

Clearly, clinical benefit with EGFR-targeting antibodies seems to be restricted to a particular subgroup of mCRC patients. However, no validated predictive factor is currently available to improve the rational administration of these therapies in this patient population. Such factors are critically needed, especially if we consider the high cost of these new therapeutics[6] and their expected future integration in regimens administered in earlier clinical stages, including first-line treatment of mCRC and adjuvant chemotherapy in stage III localized disease.

Somatic mutations of EGFR tyrosine kinase domain are associated with exquisite sensitivity to EGFR-tyrosine kinase inhibitors erlotinib and gefitinib in non-small cell lung cancer (NSCLC) [7-9], but such mutations are rare or absent in CRC $[5,10]$. EGFR protein expression, as evaluated by immunohistochemistry, does not correlate with response $[2,4,11]$ and only specific treatment-induced skin rash seems associated with tumor response and progression-free survival [2].

Recent retrospective data have suggested that EGFR amplification or KRAS exon 1 somatic mutations may allow a better selection of patients who are candidates for EGFR targeting [12,13]. In a first study [12], an increase in EGFR copy number identified by FISH (fluorescence in situ hybridization) was found in all but one responding patients, while four recent studies identified no or few cetuximab responders in KRAS mutated patients [13-17].

In the present retrospective study of 32 patients with EGFR-positive mCRC treated with cetuximab-based combination, we have analyzed EGFR copy number by FISH and sequenced the extracellular domains (ECD) of EGFR, as well as KRAS exon 1, and correlated these data with clinical outcome.

\section{Methods \\ Patients and treatment}

We retrospectively assessed 32 patients with EGFR-positive mCRC treated with cetuximab-irinotecan combination at the Institut PAOLI-CALMETTES, Marseille, France between March 2004 and July 2005 who were evaluable for tumor response and had available pre-treatment frozen and/or formalin-fixed and paraffin-embedded tumor tissues (from primary and/or metastatic tumor tissue). EGFR positivity was defined by at least $1 \%$ malignant cells demonstrating EGFR immunostaining (antibody from Zymed Laboratories, Inc., San Francisco, 1/20, digested with pepsin). In 26 patients, cetuximab was used according to official registration in irinotecan-resistant patients and administered as a loading dose of $400 \mathrm{mg} / \mathrm{m} 2$ intravenously, followed by $250 \mathrm{mg} / \mathrm{m} 2$ once a week until progression, in combination with irinotecan $180 \mathrm{mg} / \mathrm{m}^{2}$ every other week. In addition, 6 patients received cetuxi$\mathrm{mab} /$ irinotecan in specific clinical trials evaluating:

- a dose escalation of cetuximab in irinotecan-resistant patients $(n=3)$

- cetuximab in combination with Folfiri as first-line treatment $(n=2)$ or as second-line treatment after failure of first-line fluoropyrimidine/oxaliplatin $(n=1)$.

Tumor evaluation was performed with appropriate methods within four weeks of treatment initiation and repeated during treatment every 2 months for the first 6 months and then every 3 months until disease progression. WHO criteria of response were used [18]. Briefly, the 
sum of products of target lesions was calculated and response was determined as follows: complete response (CR), disappearance of all target lesions without any residual lesion; partial response (PR), 50\% or more decrease in target lesions; progressive disease (PD), 25\% or more increase in the size of measurable lesions or appearance of new lesions; stable disease (SD), neither PR or PD criteria are met. This study was approved by an institutional review board and patient consent for analysis of stored biological samples, in relation with clinical data including imagery data, was verified for all patients included.

\section{EGFR copy number by FISH}

Formalin-fixed paraffin-embedded (FFPE) tissue sections $(5 \mu \mathrm{m})$ were placed in pretreatment solution for $60 \mathrm{~min}$ at $80^{\circ} \mathrm{C}$, and digested with pepsin solution for $15 \mathrm{~min}$ at $37^{\circ} \mathrm{C}$. Dual-color, dual-target FISH assays were done with the SPEC EGFR/CEN7 Dual Color Probe Kit (ZytoVision, Bremerhaven, Germany). Tissue sections, covered with $10-\mu \mathrm{L}$ probe solution, were incubated at $75^{\circ} \mathrm{C}$ for $10 \mathrm{~min}$ to co-denature EGFR and CEN7 (chromosome seven $\alpha$ centromeric) probes and allowed to hybridize overnight at $37^{\circ} \mathrm{C}$. Codenaturation and hybridization were done sequentially in a microprocessor-controlled system (Hybridizer, DakoCytomation, Glostrup, Denmark). Posthybridization stringency wash was done in a water bath at $37^{\circ} \mathrm{C}$ for $5 \mathrm{~min}$. After washing 4 times and drying at room temperature for $15 \mathrm{~min}$, tissue sections were covered with 4'-6-diamidino-2-phenylindole (DAPI/Antifade Solution, ZytoVision, Bremerhaven, Germany) for chromatin counterstaining before microscopy. Sample material was evaluated by fluorescence microscopy (Leica. DM RXA). Filter sets for the following wavelength ranges were required: EGFR (ZyGreen), excitation at $503 \mathrm{~nm}$ and emission at $528 \mathrm{~nm}$, similar to FITC; chromosome 7 (ZyOrange), excitation at $547 \mathrm{~nm}$ and emission at 572 nm, similar to Rhodamine.

Two independent observers (SE and AL) scored at least 100 non-overlapping interphase nuclei for the number of copies of EGFR and CEN7 by use of predefined scoring guidelines. The negative controls consisted of a healthy colorectal mucosa adjacent to malignant disease; the control for amplified EGFR was an amplified colonic adenocarcinoma. FISH patterns were defined as described in [19] : Briefly, the samples were grouped as follows: normal disomy, two gene copies in more than $90 \%$ of cells; trisomy, three gene copies in more than $10 \%$ of cells and ratio gene/chromosomes $\leq 2$; low polysomy, at least four gene copies in more than $10 \%$ but fewer than $40 \%$ of cells and ratio gene/chromosomes $\leq 2$; high polysomy, at least four gene copies in more than $40 \%$ cells and ratio gene/ chromosomes $\leq 2$; and gene amplification, ratio gene/ chromosome more than two or 15 gene copies in at least
$10 \%$ of cells. Trisomy and low polysomy were not considered as increases in EGFR copy number. Tumors showing high polysomy and/or gene amplification were considered to be FISH positive and as significant increases in EGFR copy number.

\section{DNA extraction and mutation analyses}

DNA was extracted from frozen $(n=20)$ or FFPE colorectal cancer samples $(\mathrm{n}=12)$ with the QIAamp DNA minikit (Qiagen). For FFPE tissues, samples were obtained by pinching tissue fragments within a tumor zone under microscopic control. Exon 1 of KRAS, the site of the most frequent activating mutations in codons 12 and 13, and exons 6 to 14 of EGFR, corresponding to the transmembrane and extracellular domains, were sequenced after PCR amplification of each exon using the BigDye terminator kit v1.1 (Applied Biosystems) and the PhredPhrapConsed package. Genotypes were assessed with the GeneMapper software (Applied Biosystems).

\section{Statistical analyses}

Fischer's exact test was used to calculate p-values for the association between genetic parameters and response to cetuximab. Progression-free survival (PFS) was calculated from the date of cetuximab initiation to the date of disease progression, date of death if it occurred before progression, or date of last news. Overall survival (OS) was calculated from the date of cetuximab initiation to the date of death or the date of last news. Survivals were estimated with the Kaplan-Meier method. Survival curves were compared using the log-rank test. Analysis was carried out using the R software. The level of significance was set at $\mathrm{p}$ $=0.05$.

\section{Results \\ Patient population}

Patient characteristics are summarized in table 1. Cetuximab was administered after failing 2 or more regimens in 22 patients. Twenty-four patients had been previously exposed to fluoropyrimidines, irinotecan and oxaliplatin. Median follow-up was 19.1 months. An objective response was observed in 9 patients $(\mathrm{RR}=28 \%$; CI95\%, 15-45\%), and 12 patients experienced stable disease, which lasted 6 months or more for 2 patients. Eleven patients progressed at the first evaluation. Median progression-free and overall survivals were 4.1 months (CI95\%, 3.6-6.3) and 17.2 months (CI95\%, 13.8-NR), respectively.

\section{EGFR copy numer analysis}

No authentic regional amplification was observed. An increased EGFR copy number was noted in 12 patients (Table 2), but was considered as significant in only 2 patients, corresponding to high polysomy (patients 1 and 3 , Figure 1). Both patients responded to cetuximab. 
Table I: Patient population

\begin{tabular}{lcc}
\hline & \multicolumn{2}{c}{ Patients } \\
\hline Characteristics & number & percentage \\
\hline All patients & 16 & \\
Sex & & \\
Male & 16 & $50 \%$ \\
Female & 16 & $50 \%$ \\
Age, years & & \\
Median & & 58 \\
Range & & $36-78$ \\
Tumor site & & \\
Colon & 21 & $65 \%$ \\
Rectum & 11 & $35 \%$ \\
Previous adjuvant chemotherapy & & \\
Yes & 10 & $31 \%$ \\
No & 22 & $69 \%$ \\
Line of cetuximab use & & \\
Median & & 3 \\
Range & & $1-5$ \\
Response status & & \\
CR & & \\
PR & & \\
SD & 9 & $37.5 \%$ \\
PD & 12 & $34.4 \%$ \\
\hline
\end{tabular}

$\mathrm{CR}=$ Complete response, $\mathrm{PR}=$ Partial response, $\mathrm{SD}=$ Stable disease and $\mathrm{PD}=$ Progressive disease were defined as described in the methods section.

\section{EGFR sequencing}

We sequenced EGFR exons 6 to 14 coding for the transmembrane and extracellular domains. No mutation was found, but a heterozygous ( 9 patients) or homozygous ( 3 patients) point substitution $\mathrm{G} \rightarrow \mathrm{A}$ on exon 13 , resulting in the amino acid substitution of arginine by lysine in position $521(\mathrm{R} 521 \mathrm{~K})$, was detected in 12 patients. This variant was observed in 11 of 21 patients achieving objective response ( 4 patients) or stable disease ( 7 patients) and in 1 of 11 patients with rapidly progressive disease (defined as progression at time of the first evaluation) ( $\mathrm{p}=0.02$, Fischer's exact test) (Table 2). As shown in figure 2A, median PFS and OS were significantly better in patients with the $\mathrm{R} 521 \mathrm{~K}$ variant than in wild-type patients $(5.7$ [CI95\%, 4.3-NR] vs. 3.2 [CI95\%, 2.5-4.7] months; $\mathrm{p}=$ 0.041, log-rank test for PFS; 20.1 [CI95\%, 16-NR] vs. 13.8 [CI95\%, 7.7-NR] months; $\mathrm{p}=0.03$ log-rank for OS).

\section{KRAS mutations}

Sequencing of KRAS exon 1 was performed and correlated with clinical outcome (Table 2). Fourteen patients displayed KRAS exon 1 mutations (codon 12 for 10 patients, codon 13 for 4 patients). Of the 32 genotyped tumors, 19 were metastases and 13 were primary tumors. In six patients, paired primary and metastatic tumors were available; no discordance was observed between the genotypes. In 9 responding patients, 2 had a KRAS mutation
(22\%), whereas 12 of 23 (52\%) nonresponding patients had a KRAS mutation. This difference was not statistically significant ( $\mathrm{p}=0.234$, Fischer's exact test). As shown in figure 2B, PFS was similar in KRAS-nonmutated and KRAS-mutated patients: median PFS was 3.9 months (CI 95\%, 2.5-11) and 4.7 months (CI 95\%, 2.7-11.3) ( $\mathrm{p}=$ 0.968 , log-rank test) in KRAS-nonmutated and KRASmutated patients, respectively. Overall survival was better in KRAS-nonmutated (20.8 months [CI 95\%, 14.5-NR]) than in KRAS-mutated patients (13.8 months [CI 95\%, 11.5-NR]), however this difference did not reach statistical significance ( $\mathrm{p}=0.472$, log-rank test).

\section{Clinical features of KRAS-mutated benefiting from cetuximab based-treatment}

To better examine the clinical relevance of response or long-lasting stable disease obtained by cetuximab-irinotecan combination in 3 patients with KRAS-mutated tumors, their medical records were reviewed. The first patient (Pt 6) was a 53-year-old woman presenting liver metastases from a primary pT2N2 colon cancer resected in May 2003. She had received adjuvant LV-5FU (infusional 5FU/folinic acid) chemotherapy between May 2002 and October 2003. A first hepatic relapse occurred in January 2004 and was treated with two courses of Folfox (5FU, folinic acid, oxaliplatin) followed by Folfiri (5FU, folinic acid, irinotecan) due to allergic reaction after oxaliplatin infusion. The patient achieved a partial response and a right hepatectomy for metastasis removal was performed on April 2004, followed by six cycles of Folfiri in August 2004. She had a second hepatic relapse in September 2004 and in October 2004 was subjected to radiofrequency ablation which failed, resulting in the appearance of an additional hepatic lesion. The patient started cetuximab in association with irinotecan in January 2005 and achieved an authentic partial response allowing surgical removal in April 2005 (Figure 3A). Surgery was pathologically complete and the patient was alive in complete remission at time of last news in May 2006.

The second responding patient with a KRAS mutation (Pt 7) was a 52-year-old woman who had been treated in June 1999 for a primary adenocarcinoma of the rectum classified pT4N2. The patient received post-operative radiochemotherapy with Fufol (Bolus 5FU/folinic acid) on week 1 and 5. In February 2000, she had liver metastases that were completely surgically removed. In December 2000, she had a second hepatic relapse and received an association of 5FU/irinotecan/oxaliplatin for 2 months allowing her to be a candidate for a second complete surgical removal which was performed in April 2001. On January 2003, she experienced a third relapse involving retroperitoneal lymph nodes which was treated with Folfiri until May 2003, when a partial response was achieved. Maintenance with capecitabine was initiated and contin- 
Table 2: Molecular Alterations in tumors of metastatic colorectal cancer patients

\begin{tabular}{|c|c|c|c|c|c|c|c|c|c|c|}
\hline Pt number & Sex & Age & $\begin{array}{c}\text { Previous } \\
\text { adjuvant } \mathrm{CT}\end{array}$ & $\begin{array}{c}\text { Type of } \\
\text { adjuvant CT }\end{array}$ & $\begin{array}{l}\text { Previous } \\
\text { regimen for } \\
\text { metastatic } \\
\text { disease }\end{array}$ & $\begin{array}{c}\text { Tumor Best } \\
\text { response }\end{array}$ & $\begin{array}{l}\text { Time to } \\
\text { progression } \\
\text { (weeks) }\end{array}$ & KRAS exon I & $\begin{array}{c}\text { EGFR } \\
\text { exon } 13\end{array}$ & $\begin{array}{c}\text { EGFR copy } \\
\text { Number } \\
\text { (FISH) }\end{array}$ \\
\hline \multicolumn{11}{|c|}{ Responders } \\
\hline 1 & $\mathrm{~F}$ & 70 & 0 & & - & $P R$ & 10 & Wild-type & R52IK & $\begin{array}{l}\text { high } \\
\text { polysomy }\end{array}$ \\
\hline 2 & $M$ & 62 & 0 & & Folfirinox & PR & $94 *$ & Wild-type & & trisomy \\
\hline 3 & $\mathrm{~F}$ & 56 & 0 & & Folfiri, Folfox & $P R$ & 9 & Wild-type & & $\begin{array}{c}\text { high } \\
\text { polysomy }\end{array}$ \\
\hline 4 & $M$ & 37 & 0 & & $\begin{array}{c}\text { Folfiri, } \\
\text { Folfox, xelox }\end{array}$ & PR & 44 & Wild-type & & $\begin{array}{l}\text { low } \\
\text { polysomy }\end{array}$ \\
\hline 5 & $\mathrm{~F}$ & 44 & 0 & & Folfiri, Folfiri & PR & 33 & Wild-type & R52IK & disomy \\
\hline 6 & $\mathrm{~F}$ & 54 & 1 & LV5FU & Folfiri & PR & 67 & Gly|3Asp & & disomy \\
\hline 7 & $\mathrm{~F}$ & 52 & i & Fufol & $\begin{array}{l}\text { Folfirinox, } \\
\text { Folfiri, } \\
\text { LV5FU- } \\
\text { mitomycine }\end{array}$ & PR & 42 & Gly I 2Asp & R52IK & disomy \\
\hline 8 & $M$ & 56 & 0 & & Foflfox & PR & 25 & Wild-type & & disomy \\
\hline 9 & $M$ & 66 & 1 & Fufol & Folfiri, Folfox & PR & $24 *$ & Wild-type & R52IK & trisomy \\
\hline \multicolumn{11}{|c|}{ Non-responders } \\
\hline 10 & $\mathrm{~F}$ & 68 & 0 & & $\begin{array}{l}\text { Folfiri, } \\
\text { Xeloda, } \\
\text { Xelox }\end{array}$ & SD & 17 & Wild-type & R52IK & trisomy \\
\hline 11 & $\mathrm{~F}$ & 74 & 1 & LV5FU & Folfiri & SD & 10 & Gly $12 \mathrm{Val}$ & & disomy \\
\hline 12 & $M$ & 61 & 0 & & Folfirinox & SD & 18 & Gly13Asp & R52IK & disomy \\
\hline 13 & $\mathrm{~F}$ & 71 & 0 & & $\begin{array}{l}\text { Xelox } \\
\text { Avastin- } \\
\text { Xeliri }\end{array}$ & SD & 15 & Gly 12Asp & & disomy \\
\hline 14 & $M$ & 59 & 0 & & $\begin{array}{l}\text { LV5FU, } \\
\text { Folfiri, Folfox }\end{array}$ & SD & 24 & Gly 12Cys & R52IK & trisomy \\
\hline 15 & $M$ & 71 & 0 & & $\begin{array}{c}\text { Folfox, } \\
\text { Irinotecan }\end{array}$ & SD & 14 & Wild-type & & disomy \\
\hline 16 & $\mathrm{~F}$ & 60 & 1 & Fufol & $\begin{array}{l}\text { Folfiri, } \\
\text { Folfox, Cape, } \\
\text { LV5FU }\end{array}$ & SD & 17 & Wild-type & & trisomy \\
\hline 17 & $M$ & 65 & 0 & & $\begin{array}{l}\text { Folfirinox, } \\
\text { Folfiri }\end{array}$ & SD & 18 & Wild-type & & $\begin{array}{c}\text { low } \\
\text { polysomy }\end{array}$ \\
\hline 18 & $M$ & 66 & 0 & & Folfiri & SD & 17 & Wild-type & R52IK & disomy \\
\hline 19 & $\mathrm{~F}$ & 45 & 0 & & $\begin{array}{l}\text { Folfox, } \\
\text { Xelox }\end{array}$ & SD & 17 & Wild-type & R52IK & NE \\
\hline 20 & $\mathrm{~F}$ & 42 & 0 & & Folfirinox & SD & 21 & Gly 12Asp & R52IK & trisomy \\
\hline 21 & $M$ & 62 & 1 & Folfox & Xeliri & SD & 36 & Gly13Asp & R52IK & disomy \\
\hline 22 & $M$ & 58 & 1 & Folfiri & Xelox, Xeliri & PD & NA & Gly13Asp & & disomy \\
\hline 23 & $M$ & 75 & 1 & Xelox & Xeliri & PD & NA & Wild-type & & trisomy \\
\hline 24 & $M$ & 81 & 0 & & Xelox, Folfiri & PD & NA & Gly 12 Val & & disomy \\
\hline 25 & $\mathrm{~F}$ & 55 & 0 & & $\begin{array}{c}\text { Xelox } \\
\text { Avastin- } \\
\text { Xeliri }\end{array}$ & PD & NA & Gly I2Asp & & disomy \\
\hline 26 & $M$ & 60 & 1 & LV5FU & $\begin{array}{l}\text { Folfiri, Folfiri, } \\
\text { Folfox }\end{array}$ & PD & NA & Wild-type & & NE \\
\hline 27 & $M$ & 59 & 0 & & $\begin{array}{l}\text { Folfiri, Folfiri/ } \\
\text { Folfox, } \\
\text { Folfox }\end{array}$ & PD & NA & Gly 12Asp & & NE \\
\hline 28 & $\mathrm{~F}$ & 58 & 1 & LV5FU & Folfiri, Xelox & PD & NA & Gly12Asp & & disomy \\
\hline 29 & $M$ & 51 & 0 & & Folfox, Folfiri & PD & NA & Wild-type & & disomy \\
\hline 30 & $\mathrm{~F}$ & 66 & 0 & & Folfiri, Xelox & PD & NA & Wild-type & R52IK & trisomy \\
\hline 31 & $\mathrm{~F}$ & 56 & 0 & & - & PD & NA & Wild-type & & disomy \\
\hline 32 & $\mathrm{~F}$ & 78 & 0 & & $\begin{array}{c}\text { Folfox, } \\
\text { Folfiri, Cape }\end{array}$ & PD & NA & Gly 12 Val & & disomy \\
\hline
\end{tabular}

$\mathrm{F}=$ female, $\mathrm{M}=$ Male, Folfox = oxaliplatin, fluorouracil, and folinic acid; Xelox = capecitabine, oxaliplatin; Folfiri = irinotecan, fluorouracil, and folinic acid; Xeliri = Capecitabine, irinotecan; Folfirinox = oxaliplatin, irinotecan, fluorouracil, and folinic acid; LV5FU = infusional FU and folinic acid; Fufol $=$ bolus fluorouracil and folinic acid; $P R=$ partial response. $S D=$ stable disease. $P D=$ progressive disease. $R 52 I K=$ point substitution $G \rightarrow A$ on exon 13 EGFR resulting in the amino acid substitution Arg to Lys in position 52I. NA = not applicable. NE = not evaluable. 


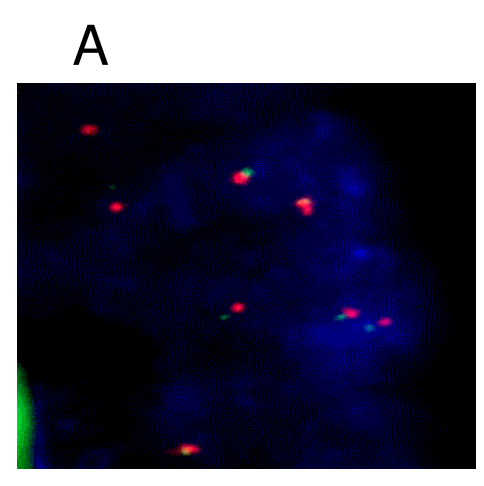

$\mathrm{D}$

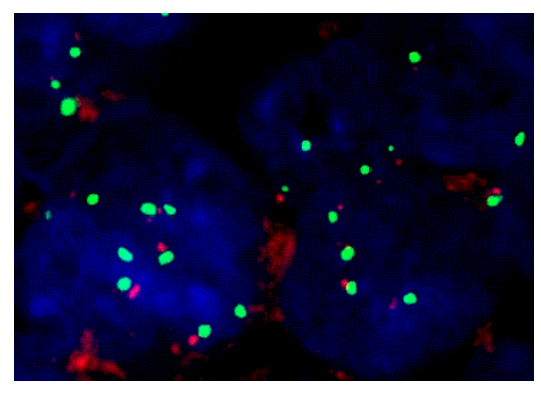

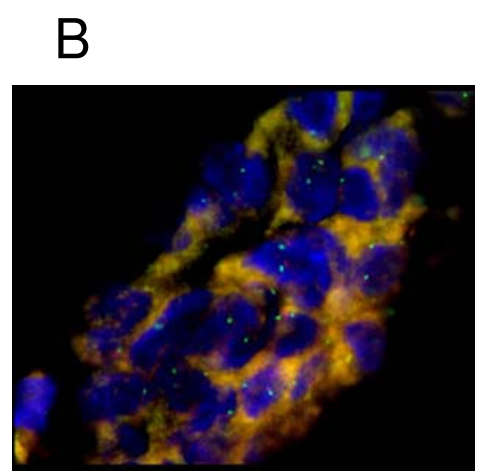
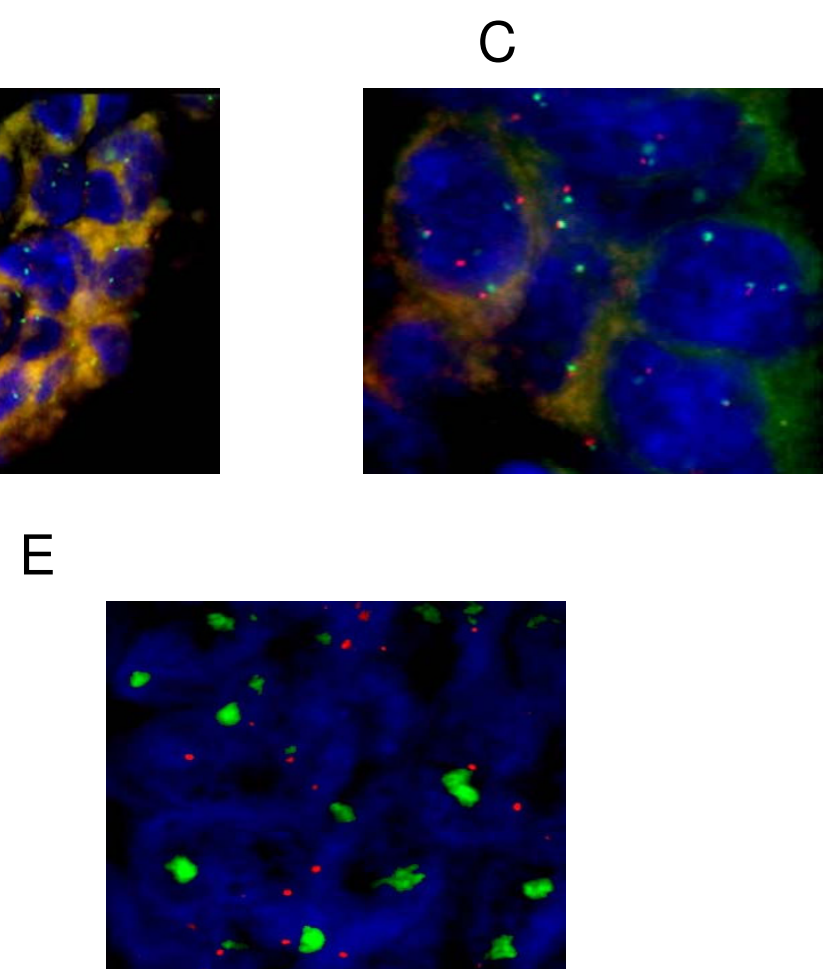

Figure I

Dual color FISH assays for probes of EGFR (green) and chromosome seven (CEP7, red). (A) Balanced disomy in healthy colorectal mucosa. (B) Balanced disomy in tumor of patient I5. (C) Balanced low polysomy in tumor of patient 4. (D) High polysomy in tumor of patient I. (E) Amplification in a control tumor.

ued until October 2003 when disease progressed on both lymph nodes and the liver. A palliative treatment was started combining 5FU and mitomycin $\mathrm{C}$ with no response. The patient started cetuximab with irinotecan in March 2004, when the compound became available in France. She experienced a partial response until January 2005 (Figure 3B), when she developed bone metastases with spinal compression. She died in February 2005.

Finally, a third patient (pt 21) with a KRAS mutation achieved long-lasting stable disease ( 8 months), under cetuximab-irinotecan treatment. This 62-year old man had been treated in 2004 for a pT3N2 colon cancer by surgery followed by adjuvant Folfox. In December 2004, while he was receiving Folfox, he developed liver metastases which were surgically removed. Post-operative treatment was initiated in March 2005 with an association of capecitabine/irinotecan, but lung metastases occurred under treatment. A combination of cetuximab and irinotecan was started in June 2005 and continued with stable disease until February 2006 when peritoneal and lung progression occurred. The patient died in August 2006.

\section{Discussion}

In this retrospective and preliminary study including 32 mCRC patients receiving cetuximab-based treatment, we have analyzed molecular factors that have been suggested to regulate activity of EGFR-targeted approaches.

\section{EGFR copy number}

Using a FISH-based assay, we evaluated EGFR copy number and did not observe any EGFR amplification (ratio EGFR to Control probes $>2$ or $\geq 15$ gene copies in $\geq$ $10 \%$ of cells), although trisomy or polysomy was observed in 12 patients. Only 2 patients displayed an increase in EGFR copy number that reached the definition of high polysomy ( $\geq$ four gene copies in $\geq 40 \%$ cells). However, these 2 patients were objective responders to cetuximab. In previous studies, an increase in EGFR gene copy number has been observed in 0.6 to $31 \%$ of CRC. These variations may be due in part to the techniques used to evaluate amplification, which include FISH, CISH or real-time quantitative PCR. Moreover, amplifications limited to the EGFR locus must be distinguished from extracopies of the entire chromosome 7 which contains the EGFR gene (polysomy). In a study involving 31 

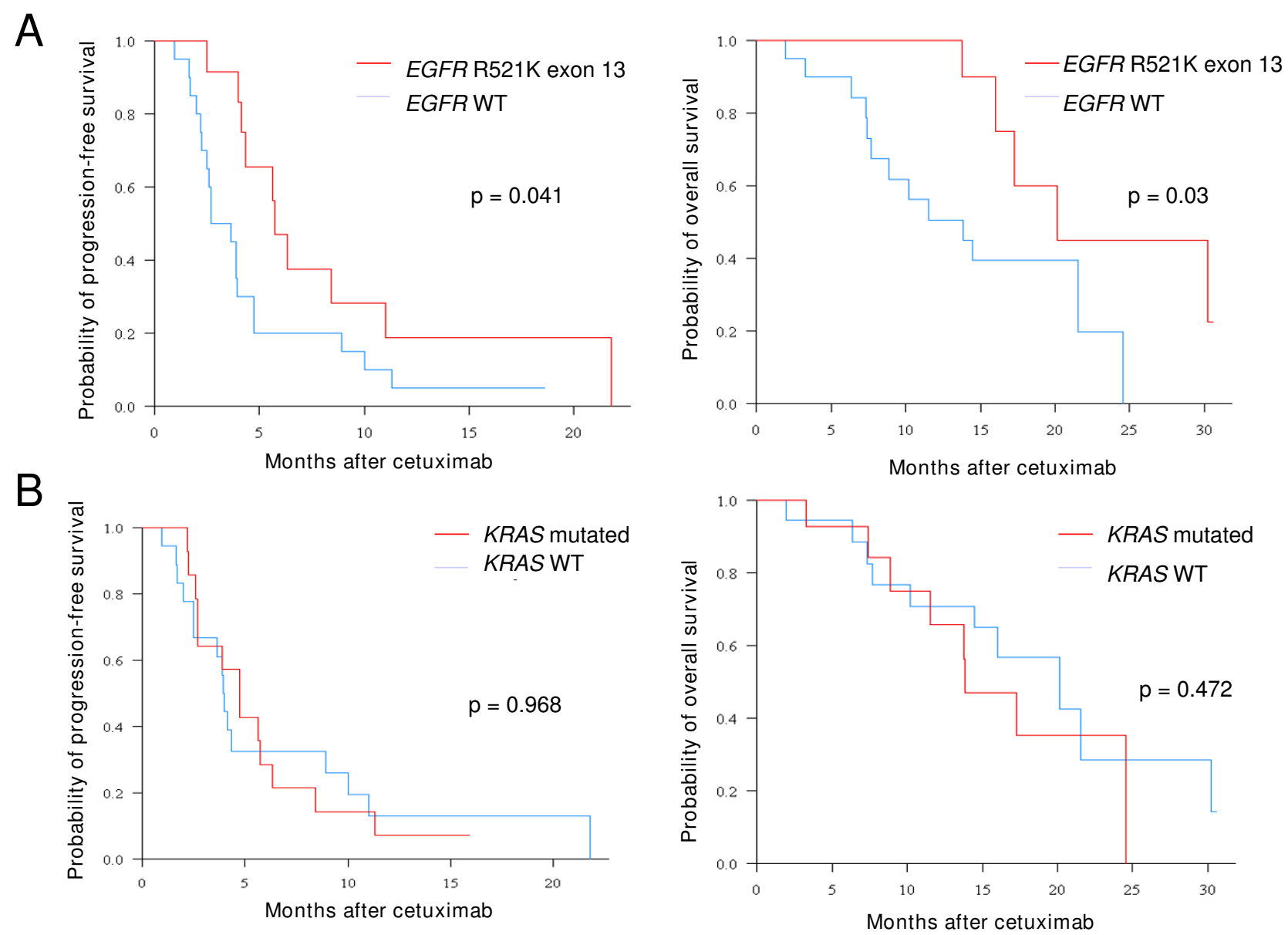

Figure 2

Survivals according to EGFR and KRAS genotypes. A/ Progression-free survival (PFS) (Left) and overall survival (OS) (Right) curves of patients with EGFR R52IK variant and wild-type. B/ PFS (Left) and OS (Right) curves of patients with a KRASmutated and nonmutated tumor.

patients[12], Moroni et al observed an increase in EGFR copy number in 8 of the 9 cetuximab-responders but only in 1 of the 20 nonresponder patients who were assessable by FISH, suggesting that this increase may represent a strong positive predictive factor for response to this compound. Of note, an authentic amplification was found in 7 of these 9 patients with increased EGFR copy number. However, the same group recently reported no actual EGFR amplification but only polysomy in 58 FISH-analyzed tumors from mCRC patients receiving panitumumab. These authors have concluded that the previously observed amplification frequency could have been overestimated by scoring as amplified some tumors with only very limited foci of amplification. Nevertheless, this study still suggested a significant association between EGFR copy number and response and survival [20]. Other groups have reported a lower rate of copy gain, corre- sponding most often to polysomy $[13,21-23]$. In one of these studies which is consistent with our own results, only 3 patients out of 30 displayed an increase in EGFR copies as evaluated by CISH [13]; these 3 patients responded to cetuximab. Thus, a significant increase in EGFR copy number may be associated with a high probability of response, even though this molecular alteration may be relatively rare in mCRC. Furthermore, regarding the significant number of responding patients without any significant increase in EGFR copy number in both Lievre et al's study (8 out of 11 responders) and ours (7 out of 9 responders), we do not believe that this parameter should be considered as a prerequisite for cetuximab activity. 

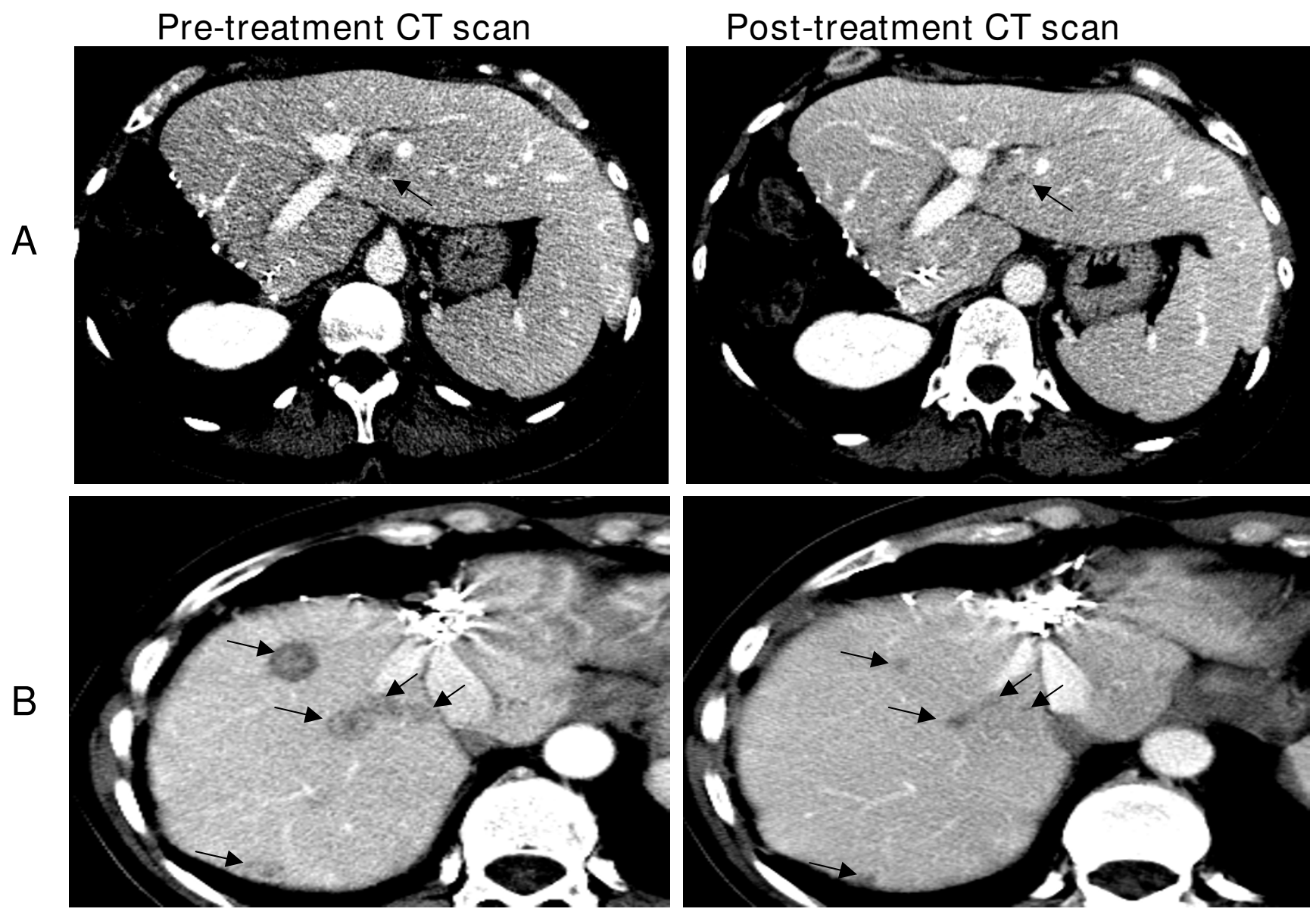

Figure 3

Objective partial responses to cetuximab-based treatment in patients with KRAS- mutated tumors. (A) Pre- and post-cetuximab CT scan showing partial tumor response allowing surgical resection to be performed in patient 6. (B) Pre- and post-cetuximab CT scan demonstrating a major tumor response to cetuximab-based treatment in patient 7 .

\section{KRAS mutations}

Recent retrospective data from several independent studies have shown a very negative association between KRAS exon 1 mutations and cetuximab response in mCRC patients. A first group found no KRAS mutations in tumors from 11 cetuximab-responding patients, whereas 13 of the 19 nonresponders $(\mathrm{p}=0.0003)$ had a KRASmutated tumor, leading the authors to suggest that KRAS mutational status could serve to exclude cetuximab use in mCRC[13]. A second recently published study involving 59 refractory mCRC patients receiving cetuximab-based treatment confirmed these data by reporting no mutations in all 12 responding patients, with a significantly worse time-to-progression in patients with a KRAS mutation[14]. Additionally, a third report has shown that mutations affecting either KRAS or BRAF are predictive and prognostic indicators in mCRC patients, and are inversely correlated with response to anti-EGFR mono- clonal antibodies [16]. Another study evaluating KRAS/ $B R A F$ mutation status in 80 patients receiving cetuximab as single-agent found only 3 KRAS mutated tumors out of 27 patients who experienced a clinical benefit, but 27 out of 53 nonresponding patients [15]. Finally, recent data from 27 mCRC patients observed only one responder out of 10 mutated tumors compared to 9 out of 17 non mutated tumors[17]. We found a similar trend in our study, although our observations did not reach statistical significance. Moreover, pooling all published studies evaluating this putative association further suggests that KRAS mutations strongly negatively affect the probability of objective response to cetuximab treatment. In these studies, the response rate in KRAS mutated tumors was 9 out of 115 (7.8\%, CI95\%: 3.6-14.3\%) versus 81 out of 192 (42.2\%, CI95\%: $35.1-49.5 \%)$ in wild type tumors ( $\mathrm{p}=$ $3.510^{-10}$, chi-2 test). However, we did not find any statistically significant difference in OS or PFS in patients with 
KRAS-mutated and wild-type tumors. Although this lack of difference may be reasonably attributed to the limited sample size, data presented in our study also demonstrated that authentic and clinically relevant tumor responses and/or long-term stabilization may be achieved with cetuximab-based treatment in patients with KRASmutated tumors. Accordingly, we believe that it could be premature to absolutely exclude cetuximab use in these patients.

\section{A variant of EGFR extracellular region}

Activating mutations of the intracellular kinase domain of EGFR have been associated with human malignancies and responsiveness to small molecule EGFR tyrosine kinase inhibitors $[5,10,12]$. These mutations are rare or absent in mCRC, and are thus unlikely to explain the reported antitumor activity of cetuximab in this population. Nevertheless, little is known about the extracellular region of EGFR which represents the binding site of cetuximab. We sequenced this entire domain and did not find any mutations. However, we observed in 12 patients $(37 \%)$ a $\mathrm{G} \rightarrow \mathrm{A}$ substitution in exon 13, which encodes a part of the extracellular region of the receptor. The resulting amino acid substitution Arg to Lys is located at the boundary between EGFR domain III, which represents the direct interaction site with cetuximab, and domain IV [24]. In our study, this variation was observed in 11 patients achieving at least a stable disease as their best response, but only in 1 patient with progressive disease at its first evaluation. Moreover, PFS and OS after cetuximab treatment were significantly better in the subset of patients displaying this variant.

This substitution, considered as a polymorphism (rs11543848 in SNPdb, heterozygosity of 0.41), may be relatively conservative, as both Arg and Lys are positively charged amino acids with similar side chains. It is also found in DNA from normal human lymphocytes [25] obtained from individuals without malignant diseases with a frequency of about $20 \%$ (homozygous variant) to $50 \%$ (heterozygous variant) in the general population [26].

Furthermore, EGFR exon 13 R521K variant has been already described in other EGFR expressing tumors, such as gliomas and lung cancer [27]. This EGFR polymorphism, previously described as codon 497 (R497K) according to an older nomenclature, has been negatively associated with pelvic recurrence in patients with rectal cancer treated with chemoradiation [28]. Recent data have shown that it correlates with a decrease in EGFR phosphorylation, decreased invasion, lower nodal involvement, reduced subsequent metastasis, and longer disease-free and overall survival in stage II/III colorectal carcinoma patients who have received curative surgery[26]. In addi- tion, R521K was associated with oxaliplatin/FU efficacy in metastatic patients. Interestingly, the resulting amino acid substitution (Arg to Lys) was shown to significantly reduce TGF $\alpha$ binding and ligand-induced EGFR signaling [29]. Thus, it is tempting to speculate that EGFR variant may alter binding of its specific ligands leading to a particular phenotype of EGFR signaling. This is particularly interesting in light of very recent evidences generated from a microarray study showing that expression of EGFR ligands epiregulin and amphiregulin may predict cetuximab benefit [15]. An attenuated EGFR-mediated signaling, as putatively supposed with R $521 \mathrm{~K}$ polymorphism, could be even more sensitive to targeted receptor inhibition. Alternatively, R521K variant could also affect drug binding and/or effects. However, such preliminary hypotheses remain to be proven: we have initiated specific functional studies evaluating the correlation between cetuximab sensitivity and the EGFR exon 13 genotype in various CRC cell lines and in cellular models expressing wild type EGFR or the EGFR R521K variant. Importantly, EGFR genotyping on a larger cohort of cetuximab-treated patients, the accrual of which is currently ongoing, will be essential to confirm our findings.

\section{Conclusion}

In conclusion, genetic factors affecting cetuximab response are likely to be multiple. EGFR copy number as well as variations in amino acid composition of the extracellular region may favorably impact cetuximab activity, whereas KRAS mutations negatively alter the probability of response, without totally abolishing it. However, these data from a small-sized patient population are still preliminary. Thus, validation of these results on larger cohorts and prospective studies are imperatively needed.

\section{Abbreviations}

ECD: extracellular domain; EGFR: epidermal growth factor receptor; FISH: fluorescence in situ hybridization; mCRC: metastatic colorectal cancer.

\section{Competing interests}

The authors declare that they have no competing interests.

\section{Authors' contributions}

AG conceived of the study and its design and was in charge of its coordination. He participated in data analysis and performed data interpretation. He drafted the manuscript. SE carried out the FISH assay and helped to draft the manuscript. AL carried out the genetic analysis and participated in data analysis and interpretation. BT-S participated in the data analysis and interpretation and helped to draft the manuscript. MA participated in the data analysis. GM participated in the data analysis and interpretation. FB participated in the data interpretation and helped to draft the manuscript. BE performed the sta- 
tistical analysis. J-RD, OT and BL participated in patient treatment and data acquisition. PV helped to conceive and coordinate the study. J-PB helped to draft the manuscript. DB participated in designing, coordinating the study, and in data interpretation. He helped to draft the manuscript. SO carried out the genetic analysis, participated in data interpretation and helped to draft the manuscript. FV was in charge of patient treatment, participated in study design, coordination, and data interpretation and helped to draft manuscript. All authors read and approved the final manuscript.

\section{Acknowledgements}

We thank Christian Chabannon, M.D. Ph.D., head of the Biological Resource Centre of the Institut PAOLI CALMETTESwhere tumor tissues were frozen and stored. We are grateful to F. Birg and C. Mawas for helpful discussions. Written consent was obtained from the patient or their relative for publication of the study.

This work has been supported by Inserm, Institut Paoli-Calmettes, and grants from Ligue Nationale Contre le Cancer (Label), Institut National du Cancer (Cancéropôle PACA), and the French health ministry (PHRC 2007).

\section{References}

I. Yarden Y, Sliwkowski MX: Untangling the ErbB signalling network. Nat Rev Mol Cell Biol 200I, 2(2): I27-I 37.

2. Cunningham D, Humblet $Y$, Siena S, Khayat D, Bleiberg H, Santoro A, Bets D, Mueser M, Harstrick A, Verslype C, Chau I, Van Cutsem E: Cetuximab monotherapy and cetuximab plus irinotecan in irinotecan-refractory metastatic colorectal cancer. $N$ Engl J Med 2004, 35 I (4):337-345.

3. Van Cutsem E, Peeters M, Siena S, Humblet Y, Hendlisz A, Neyns B, Canon JL, Van Laethem JL, Maurel J, Richardson G, Wolf M, Amado RG: Open-label phase III trial of panitumumab plus best supportive care compared with best supportive care alone in patients with chemotherapy-refractory metastatic colorectal cancer. J Clin Oncol 2007, 25( I 3): | 658-I 664.

4. Saltz LB, Meropol NJ, Loehrer PJ Sr., Needle MN, Kopit J, Mayer RJ: Phase II Trial of Cetuximab in Patients With Refractory Colorectal Cancer That Expresses the Epidermal Growth Factor Receptor. J Clin Oncol 2004, 22(7): I 20I-I 208.

5. Lenz HJ, Van Cutsem E, Khambata-Ford S, Mayer RJ, Gold P, Stella P, Mirtsching B, Cohn AL, Pippas AW, Azarnia N, Tsuchihashi Z, Mauro DJ, Rowinsky EK: Multicenter Phase II and Translational Study of Cetuximab in Metastatic Colorectal Carcinoma Refractory to Irinotecan, Oxaliplatin, and Fluoropyrimidines. J Clin Oncol 2006, 24(30):4914-4921.

6. Schrag D: The price tag on progress--chemotherapy for colorectal cancer. N Engl J Med 2004, 35 I(4):3 I7-3I9.

7. Lynch TJ, Bell DW, Sordella R, Gurubhagavatula S, Okimoto RA, Brannigan BW, Harris PL, Haserlat SM, Supko JG, Haluska FG, Louis DN, Christiani DC, Settleman J, Haber DA: Activating mutations in the epidermal growth factor receptor underlying responsiveness of non-small-cell lung cancer to gefitinib. $N$ Englj Med 2004, 350(2I):2129-2I39.

8. Paez JG, Janne PA, Lee JC, Tracy S, Greulich H, Gabriel S, Herman P, Kaye FJ, Lindeman N, Boggon TJ, Naoki K, Sasaki H, Fujii Y, Eck MJ, Sellers WR, Johnson BE, Meyerson M: EGFR mutations in lung cancer: correlation with clinical response to gefitinib therapy. Science 2004, 304(5676): | 497-I500.

9. Pao W, Miller V, Zakowski M, Doherty J, Politi K, Sarkaria I, Singh B, Heelan R, Rusch V, Fulton L, Mardis E, Kupfer D, Wilson R, Kris M, Varmus $H$ : EGF receptor gene mutations are common in lung cancers from "never smokers" and are associated with sensitivity of tumors to gefitinib and erlotinib. Proc Natl Acad Sci U S A 2004.
10. Barber TD, Vogelstein B, Kinzler KW, Velculescu VE: Somatic mutations of EGFR in colorectal cancers and glioblastomas. N Engl J Med 2004, 35 I (27):2883.

II. Chung KY, Shia J, Kemeny NE, Shah M, Schwartz GK, Tse A, Hamilton A, Pan D, Schrag D, Schwartz L, Klimstra DS, Fridman D, Kelsen DP, Saltz LB: Cetuximab Shows Activity in Colorectal Cancer Patients With Tumors That Do Not Express the Epidermal Growth Factor Receptor by Immunohistochemistry. J Clin Oncol 2005, 23(9): I803-1810.

12. Moroni M, Veronese S, Benvenuti S, Marrapese G, Sartore-Bianchi A, Di Nicolantonio F, Gambacorta M, Siena S, Bardelli A: Gene copy number for epidermal growth factor receptor (EGFR) and clinical response to antiEGFR treatment in colorectal cancer: a cohort study. Lancet Oncol 2005, 6(5):279-286.

13. Lievre A, Bachet JB, Le Corre D, Boige V, Landi B, Emile JF, Cote JF, Tomasic G, Penna C, Ducreux M, Rougier P, Penault-Llorca F, Laurent-Puig P: KRAS mutation status is predictive of response to cetuximab therapy in colorectal cancer. Cancer Res 2006, 66(8):3992-3995.

14. Di Fiore F, Blanchard F, Charbonnier F, Le Pessot F, Lamy A, Galais MP, Bastit L, Killian A, Sesboue R, Tuech JJ, Queuniet AM, Paillot B, Sabourin JC, Michot F, Michel P, Frebourg T: Clinical relevance of KRAS mutation detection in metastatic colorectal cancer treated by Cetuximab plus chemotherapy. Br J Cancer 2007, 96(8): I | 66-1 I69.

15. Khambata-Ford S, Garrett CR, Meropol NJ, Basik M, Harbison CT, Wu S, Wong TW, Huang X, Takimoto $\mathrm{CH}$, Godwin AK, Tan BR, Krishnamurthi SS, Burris HA III, Poplin EA, Hidalgo M, Baselga J, Clark EA, Mauro DJ: Expression of Epiregulin and Amphiregulin and K-ras Mutation Status Predict Disease Control in Metastatic Colorectal Cancer Patients Treated With Cetuximab. J Clin Oncol 2007, 25(22):3230-3237.

16. Benvenuti S, Sartore-Bianchi A, Di Nicolantonio F, Zanon C, Moroni $M$, Veronese S, Siena S, Bardelli A: Oncogenic activation of the RAS/RAF signaling pathway impairs the response of metastatic colorectal cancers to anti-epidermal growth factor receptor antibody therapies. Cancer Res 2007, 67(6):2643-2648.

17. Frattini M, Saletti P, Romagnani E, Martin V, Molinari F, Ghisletta M, Camponovo A, Etienne LL, Cavalli F, Mazzucchelli L: PTEN loss of expression predicts cetuximab efficacy in metastatic colorectal cancer patients. Br J Cancer 2007, 97(8): | |39- I | 45.

18. WHO handbook for reporting of cancer treatment. In Pathologie Biologie Volume 48. Geneva (Switzerland), World Health Organisation Offset Publication; 1979.

19. Chung $\mathrm{CH}$, Ely K, McGavran L, Varella-Garcia M, Parker J, Parker N, Jarrett C, Carter J, Murphy BA, Netterville J, Burkey BB, Sinard R, Cmelak A, Levy S, Yarbrough WG, Slebos RJ, Hirsch FR: Increased epidermal growth factor receptor gene copy number is associated with poor prognosis in head and neck squamous cell carcinomas. J Clin Oncol 2006, 24(25):4170-4I76.

20. Sartore-Bianchi A, Moroni M, Veronese S, Carnaghi C, Bajetta E Luppi G, Sobrero A, Barone C, Cascinu S, Colucci G, Cortesi E, Nichelatti M, Gambacorta M, Siena S: Epidermal Growth Factor Receptor Gene Copy Number and Clinical Outcome of Metastatic Colorectal Cancer Treated With Panitumumab. J Clin Oncol 2007, 25(22):3238-3245.

21. Shia J, Klimstra DS, Li AR, Qin J, Saltz L, Teruya-Feldstein J, Akram M, Chung KY, Yao D, Paty PB, Gerald W, Chen B: Epidermal growth factor receptor expression and gene amplification in colorectal carcinoma: an immunohistochemical and chromogenic in situ hybridization study. Mod Pathol 2005, I 8( I 0): | 350- | 356.

22. Sauer T, Guren MG, Noren T, Dueland S: Demonstration of EGFR gene copy loss in colorectal carcinomas by fluorescence in situ hybridization (FISH): a surrogate marker for sensitivity to specific anti-EGFR therapy? Histopathology 2005 , 47(6):560-564.

23. Al-Kuraya K, Novotny H, Bavi PP, Siraj AK, Uddin S, Ezzat A, Al Sanea N, Al-Dayel F, Al-Mana H, Sheikh SS, Mirlacher M, Tapia C, Simon R, Sauter G, Terracciano L, Tornillo L: HER2, TOP2A, CCNDI, EGFR, And C-MYC oncogene amplification in colorectal cancer. J Clin Pathol 2006:jcp.2006.03828I.

24. Li S, Schmitz KR, Jeffrey PD, Wiltzius JJW, Kussie P, Ferguson KM: Structural basis for inhibition of the epidermal growth factor receptor by cetuximab. Cancer Cell 2005, 7(4):30 I-3II. 
25. Moriai T, Kobrin MS, Korc M: Cloning of a variant epidermal growth factor receptor. Biochem Biophys Res Commun 1993, I9I(3): 1034-1039.

26. Wang WS, Chen PM, Chiou TJ, Liu JH, Lin JK, Lin TC, Wang HS, Su $Y$ : Epidermal growth factor receptor $R 497 \mathrm{~K}$ polymorphism is a favorable prognostic factor for patients with colorectal carcinoma. Clin Cancer Res 2007, I 3( I 2):3597-3604.

27. Lassman AB, Rossi MR, Raizer JJ, Abrey LE, Lieberman FS, Grefe CN, Lamborn K, Pao W, Shih AH, Kuhn JG, Wilson R, Nowak NJ, Cowell JK, DeAngelis LM, Wen P, Gilbert MR, Chang S, Yung WA, Prados M, Holland EC: Molecular study of malignant gliomas treated with epidermal growth factor receptor inhibitors: tissue analysis from North American Brain Tumor Consortium Trials OI-03 and 00-0 I. Clin Cancer Res 2005, I I (2 I):784I-7850.

28. Zhang W, Stoehlmacher J, Park DJ, Yang D, Borchard E, Gil J, TsaoWei DD, Yun J, Gordon M, Press OA, Rhodes K, Groshen S, Lenz HJ: Gene polymorphisms of epidermal growth factor receptor and its downstream effector, interleukin-8, predict oxaliplatin efficacy in patients with advanced colorectal cancer. Clin Colorectal Cancer 2005, 5(2): |24-|3|.

29. Moriai T, Kobrin MS, Hope C, Speck L, Korc M: A Variant Epidermal Growth Factor Receptor Exhibits Altered Type \{alpha\} Transforming Growth Factor Binding and Transmembrane Signaling. PNAS 1994, 91 (2I):10217-1022I.

\section{Pre-publication history}

The pre-publication history for this paper can be accessed here:

http://www.biomedcentral.com/1471-2407/8/169/pre pub

Publish with Bio Med Central and every scientist can read your work free of charge

"BioMed Central will be the most significant development for disseminating the results of biomedical research in our lifetime. "

Sir Paul Nurse, Cancer Research UK

Your research papers will be:

- available free of charge to the entire biomedical community

- peer reviewed and published immediately upon acceptance

- cited in PubMed and archived on PubMed Central

- yours - you keep the copyright 